\title{
Evaluation of ultrasonically nebulised solutions for provocation testing in patients with asthma
}

\author{
SANDRA D ANDERSON, ROBIN E SCHOEFFEL, M FINNEY
}

From the Department of Thoracic Medicine, Royal Prince Alfred Hospital, Camperdown, New South Wales, Australia

ABSTRACT The airway response to the inhalation of ultrasonically nebulised distilled water was determined in 55 asthmatic patients and 16 normal subjects. We calculated the dose of wateri required to induce a $20 \%$ reduction $\left(\mathrm{PD}_{20}\right)$ in forced expiratory volume in one second $\left(F E V_{1}\right)$ by $\stackrel{\infty}{\circ}$

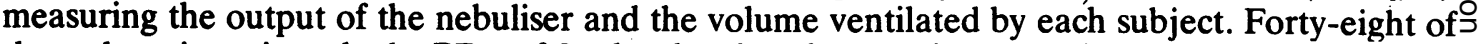
the asthmatic patients had a $\mathrm{PD}_{20}$ of $9 \mathrm{ml}$ or less but three patients required as much as $24 \mathrm{ml}$. $\mathrm{A}_{\rightarrow}^{-}$ $\mathrm{PD}_{20}$ was not recorded in the normal subjects and the challenge was stopped after $33 \mathrm{ml}$. In 120 patients the challenge was repeated within six months and the airway response was shown to be reproducible at equivalent doses of water. In a separate group of 11 patients there was, however, $\infty$ a highly significant reduction in the percentage fall in $\mathrm{FEV}_{1}$ when equivalent doses of water were given on two occasions 40 minutes apart. When the temperature of the inhaled water was increased from $22^{\circ} \mathrm{C}$ to $36^{\circ} \mathrm{C}$ eight of 10 patients had a similar change in $\mathrm{FEV}_{1}$ with equivalent doses of water. The airways obstruction induced by the inhalation of water was readily reversed with salbutamol administered by aerosol. In some patients a challenge with water or $3.6 \%$ saline $\frac{D}{\otimes}$

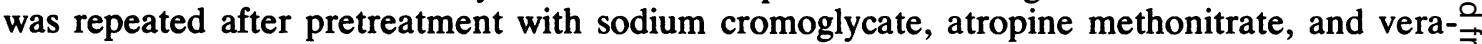
pamil hydrochloride, all given as aerosols. The airway response to the equivalent dose of water or saline was significantly reduced after treatment with sodium cromoglycate but not atropine or verapamil.

The measurement of the airway response to the inhalation of ultrasonically nebulised solutions of hypotonic and hypertonic solutions provides a new approach for the investigation of nonimmunologically mediated bronchial reactivity.

We have previously measured airway reactivity to these solutions by determining the total volume of inhaled aerosol (that is, ventilation) required to reduce the forced expiratory volume in one second $\left(\mathrm{FEV}_{1}\right)$ by $20 \%$ of the pre-challenge value. ${ }^{1}$ Other workers have measured changes in airway resistance after administering the inhaled solutions for a specified time, usually five minutes. ${ }^{2}$ There are many different ultrasonic nebulisers in use and the output of aerosol is likely to vary between nebulisers. The measurement of the volume of inhaled aerosol or the time of aerosol delivery alone does not permit a comparison to be made between asthmatic patients

Address for reprint requests: Department of Thoracic Medicine, Royal Prince Alfred Hospital, Missenden Road, Camperdown 2050, New South Wales, Australia.

Accepted 20 December 1982 studied in different laboratories.

For this reason we have determined the delivered dose required to induce a $20 \%$ reduction in FEV and compared the responses in $\mathrm{FEV}_{1}$ to equivalent doses of water under different conditions. Further- $\frac{0}{3}$ more, we have measured the proportion of a delivered dose which is retained by the patient. We have $\mathrm{S}$ also studied the effects of sodium cromoglycate, $\frac{D}{0}$ atropine methonitrate, and verapamil hydrochloride on the airway response to the same dose of inhaled N solution.

\section{Methods}

We studied 55 patients aged 11-56 years (mean 층 SD $28.5 \pm 10.8$ years) with clinically recognised asthma who were taking beta-sympathomimetic aerosols regularly for control of their symptoms. All medications were withheld for at least four hours before any test. The protocol was approved by the? ethics review committee and informed consent obtained. Sixteen non-asthmatic subjects volunteered as controls. The $\mathrm{FEV}_{1}$ was measuredo (Minato, Autospirometer, Osaka, Japan, or Cavi-o을 
tron Spirometer, California, USA) in each patient before and after the inhalation of ultrasonically nebulised distilled water and in some cases $3.6 \%$ saline.

The $\mathrm{MistoO}_{2}$ gen electronic nebuliser EN143A (California, USA) was used in all studies. This nebuliser delivers particles varying in size from 2 to $10 \mu \mathrm{m}$. The output of the nebuliser was measured by drawing known volumes of aerosol (range 10-110 l) through silica gel $(2 \times 500 \mathrm{~g})$ at varying flow rates (9-16 $1 \mathrm{~min}^{-1}$ ) with a motor blower pump (WE Collins, Massachusetts, USA). The aerosol was drawn intermittently (by turning two three-way taps) via hosing $67 \mathrm{~cm}$ or $149 \mathrm{~cm}$ long and $2.5 \mathrm{~cm}$ wide. Thus the rate and depth of normal human respiration could be simulated and the dose in millilitres delivered by the nebuliser recorded over a wide range of volumes. A regression equation was determined to relate the amount of water absorbed by the silica gel to the volume of aerosol which passed through the silica gel for each length of tubing.

For the inhalational challenge the patients breathed with a normal tidal volume (usually 500$1000 \mathrm{ml}$ ) through a two-way valve (Hans Rudolph, No 2700, Kansas, USA). Expired air passed through a canister containing $500 \mathrm{~g}$ silica gel and then a Dräger volumeter (Lüdeck, W Germany), which measured expired ventilation. The silica gel was weighed (Sartorius 1216 MP, Göttingen, Germany) before, often during, and always after each challenge.

Before each challenge with the ultrasonically nebulised aerosol the patient or subject breathed 401 of room air through the circuit. FEV, was measured before and after this procedure to determine whether any change occurred in response to the inhalation of ambient air. A fall in $\mathrm{FEV}_{1}$ greater than $15 \%$ of the initial value excluded the person from study at that time. At the beginning of the challenge 5 or $10 \mathrm{l}$ of the nebulised aerosol was inhaled and 30 seconds later three or four measurements of $\mathrm{FEV}_{1}$ were made. If during this initial challenge $\mathrm{FEV}_{1}$ was found to have fallen by $10 \%$ or more a further 5-101 of the aerosol was inhaled, and 30 seconds later a subsequent measurement of $\mathrm{FEV}_{1}$ was made. If the reduction in $\mathrm{FEV}_{1}$ was less than $10 \%$ the volumes of aerosol used in subsequent tests were $201,401,801,80 \mathrm{l}$, and $80 \mathrm{l}$, until a fall in $\mathrm{FEV}_{1}$ of at least $20 \%$ from the pre-challenge value was recorded or 3101 had been inhaled. Two minutes elapsed between the end of one challenge and the beginning of the next.

The cumulative dose of water delivered to patients was determined from their total ventilation on the basis of the regression equation for the output of the nebuliser. By subtracting the weight of exhaled water absorbed by the silica gel we could also determine the dose of water retained by the patient.

Those patients in whom severe airways obstruction was induced by the aerosols had their recovery aided by inhaling $1 \mathrm{ml}$ salbutamol $(10 \mathrm{mg})$ from a Hudson nebuliser. In other patients recovery from challenge was followed by careful observation for 15 minutes.

To determine the reproducibility of the airway response 12 patients had a second challenge with distilled water performed within six months of the first. In a separate group of 11 patients the effect of a repeat challenge with distilled water after a 40minute interval was investigated to determine whether a refractory period was present after the first challenge. Since heating occurs in nebulisers with continued use, the effect of changing the temperature from $22^{\circ} \mathrm{C}$ to $35^{\circ} \mathrm{C}$ was measured in 10 patients. The temperature of the inhaled solution was measured $10 \mathrm{~cm}$ from the mouth with a thermistor (No 408, Yellow Springs, USA).

The effect of sodium cromoglycate $(20 \mathrm{mg})$ and (separately) of atropine methonitrate $(0 \cdot 1-1.0 \%$ for 10 minutes) was investigated in nine patients who were challenged with both distilled water and $3.6 \%$ saline. A separate group of nine patients were challenged with distilled water after the administration of verapamil hydrochloride $(12.5 \mathrm{mg})$. All medications were delivered as aerosols (10-15 minutes before challenge) through a Hudson mask and Acorn nebuliser which was attached to a cylinder of compressed air giving a driving pressure of $10 \mathrm{lb} / \mathrm{in}^{2}$ $(69 \mathrm{kPa})$. The Acorn nebuliser delivered particles in the range of $2-10 \mu \mathrm{m}$. In the verapamil study isotonic saline $(5 \mathrm{ml})$ was administered by the Acorn nebuliser as a placebo control 10-15 mimutes before challenge with distilled water.

A dose-response curve was drawn ror each patient relating the fall in $\mathrm{FEV}_{1}$ (expressed as a percentage of the pre-challenge value) after each challenge (that is, 10l, 201, 40 l, etc) to the cumulative dose of aerosol water required to induce that fall in $\mathrm{FEV}_{1}$. The dose of aerosol water was determined from the ventilation required to induce the fall in FEV by using the appropriate equation for the output of the nebuliser (see below).

Bronchial reactivity to the aerosols was assessed in several ways. Firstly, the dose (in $\mathrm{ml}$ ) of the aerosol water required to induce a fall in FEV $\mathrm{F}_{1}$ of $20 \%$ of the pre-challenge level was determined from the dose-response curve for each patient. In this way the sensitivity to inhaled water could be compared within the patient population. Secondly, the response in $\mathrm{FEV}_{1}$ was compared after the same dose of an aerosol (either distilled water or $3.6 \%$ saline) 
had been given on separate occasions to the same patient.

An index of protection was used to assess the effect of a drug and was calculated as the difference between the fall in FEV $\mathrm{F}_{1}$ induced by challenge after pretreatment and the fall induced by challenge without pretreatment, expressed as a percentage of the fall induced by challenge without pretreatment. A value for protection greater than $60 \%$ has been taken as a significant drug effect.

Normal predicted values for FEV, were taken from the data of Goldman and Becklake. ${ }^{3}$

Regression coefficients were determined by the standard methods described by Snedecor and Cochran. ${ }^{4}$ The coefficient of variation for repeated measurements in the same subjects was determined by the standard deviation of the differences between the tests expressed as a percentage of the overall mean. A $t$ test was used to determine the significance of differences between paired values in the same subject. A p value less than 0.05 was taken as statistically significant.

\section{Results}

The output of the ultrasonic nebuliser was constant and linearly related to the total volume taken through the silica gel for each test. The output was unaffected by temperature, flow rate, or frequency of respiration simulated by the motor blower; but the length of tubing between the nebuliser and motor blower had a small effect. The regression equations for the output and volume for both lengths of tubing used are given in table 1 (equations 1 and 2).

There was a small reduction in FEV from the resting value in response to breathing $40^{1} 1$ of room air-mean (SD) $4.96 \%(7.9)$ in the asthmatics and $1.2 \%(1.8)$ in the normal subjects. All patients had

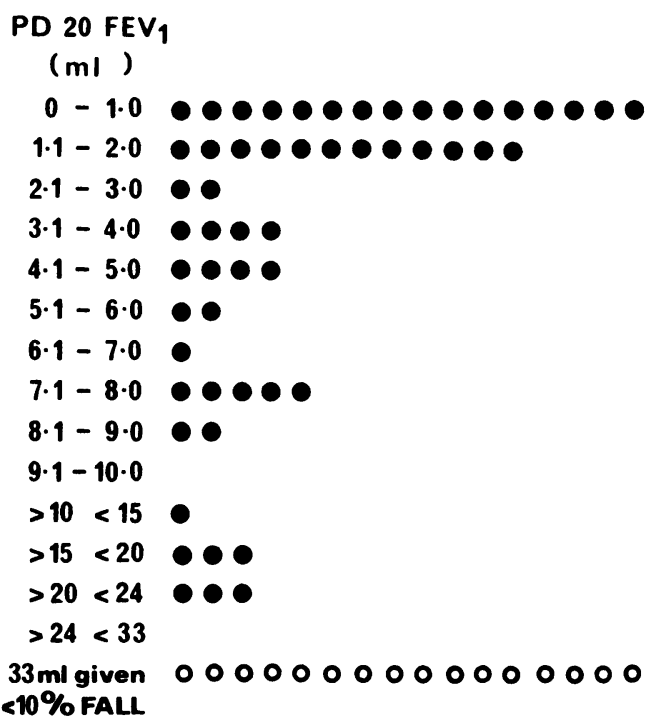

Fig 1 Dose of ultrasonically nebulised distilled water $(\mathrm{ml})$ required to induce a $20 \%$ reduction in forced expiratory volume in one second from the pre-challenge value $\left(P D_{2}\right.$ $\left.F E V_{1}\right)$ in 55 patients with clinically recognised asthma (closed circles). An inhaled dose of water $(33 \mathrm{ml})$ was given to 16 normal subjects (open circles) who had less than a $10 \%$ reduction in $F E V_{1}$.

a fall in FEV of $20 \%$ after the inhalation of distilled water and $3.6 \%$ saline. No normal subject had a fall in $\mathrm{FEV}_{1}$ of $20 \%$ or more of the initial value and the challenge was terminated after $33 \mathrm{ml}$ water or $3.6 \%$ saline had been given. The delivered doses of water required to induce a $20 \%$ fall in $\mathrm{FEV}_{1}\left(\mathrm{PD}_{20}\right)$ in the $\stackrel{2}{\sim}$ 55 patients are shown in figure 1 . There was a wide variation in the dose of water required to induce the 3 . same fall in FEV. Twenty-eight $(51 \%)$ of the $\delta$ patients had a $\mathrm{PD}_{20}$ of $2 \mathrm{ml}$ or less and $48(87 \%)$ had $₹$ a $P_{20}$ less than $10 \mathrm{ml}$. Seven patients however,

Table 1 Regression equations for ( 1 and 2 ) the output of the nebuliser $(\mathrm{ml})$ in relation to the volume (litres) of aeroso delivered; ( 3 and 4) the resting level of forced expiratory volume in one second ( $F E V$, expressed as percentage of predicted $N$ volume $(R / P \%)$ in relation to the dose $(\mathrm{ml})$ of water required to induce a $20 \%$ fall in $F E V_{1}\left(P D_{20}\right) ;(5)$ the $F E V, R / P \%$ in relation to that part of the delivered dose which was retained (DR); (6) the delivered dose (DD) in relation to dose retained (both $\mathrm{ml}$ )

\begin{tabular}{|c|c|c|c|c|c|c|c|}
\hline Equation No & $x$ & $y$ & $n$ & $a$ & $b$ & $r$ & $p$ \\
\hline $\begin{array}{l}1 \\
2 \\
3 \\
4 \\
5 \\
6\end{array}$ & $\begin{array}{l}\text { Litres* } \\
\text { Litres }{ }^{*} \\
\text { FEV, R/P\% } \\
\text { FEV, R/P\% } \\
\text { FEV,R/P\% } \\
\text { DD ml }\end{array}$ & $\begin{array}{l}\mathrm{ml} \\
\mathrm{ml} \\
\mathrm{PD}_{20} \\
\mathrm{PD}_{20} \\
\mathrm{DR}^{\mathrm{ml}} \\
\mathrm{DR} \mathrm{ml}\end{array}$ & $\begin{array}{l}18 \\
18 \\
55 \\
48 \\
44 \\
44\end{array}$ & $\begin{array}{l}0.107 \\
0.095 \\
0.16 \\
0.035 \\
0.03 \\
1 \cdot 16\end{array}$ & $\begin{array}{c}-0.21 \\
+0.11 \\
-8.65 \\
-0.15 \\
67.2 \\
-4.43\end{array}$ & $\begin{array}{l}0.97 \\
0.97 \\
0.52 \\
0.25 \\
0.09 \\
0.98\end{array}$ & $\begin{array}{l}<0.001 \\
<0.001 \\
<0.001 \\
\text { NS } \\
\text { NS } \\
<0.001\end{array}$ \\
\hline
\end{tabular}

$x=$ independent variable; $y=$ dependent variable; $n=$ number of observations; $a=$ slope of line; $b=$ intercept; $r=$ correlation $\mathbb{Q}$ coefficient; and $p=$ statistical probability.

*Tube length $67 \mathrm{~cm}$.

†Tube length $149 \mathrm{~cm}$.

$\ddagger$ Omitting seven patients with $\mathrm{PD}_{20}>10 \mathrm{ml}$. 


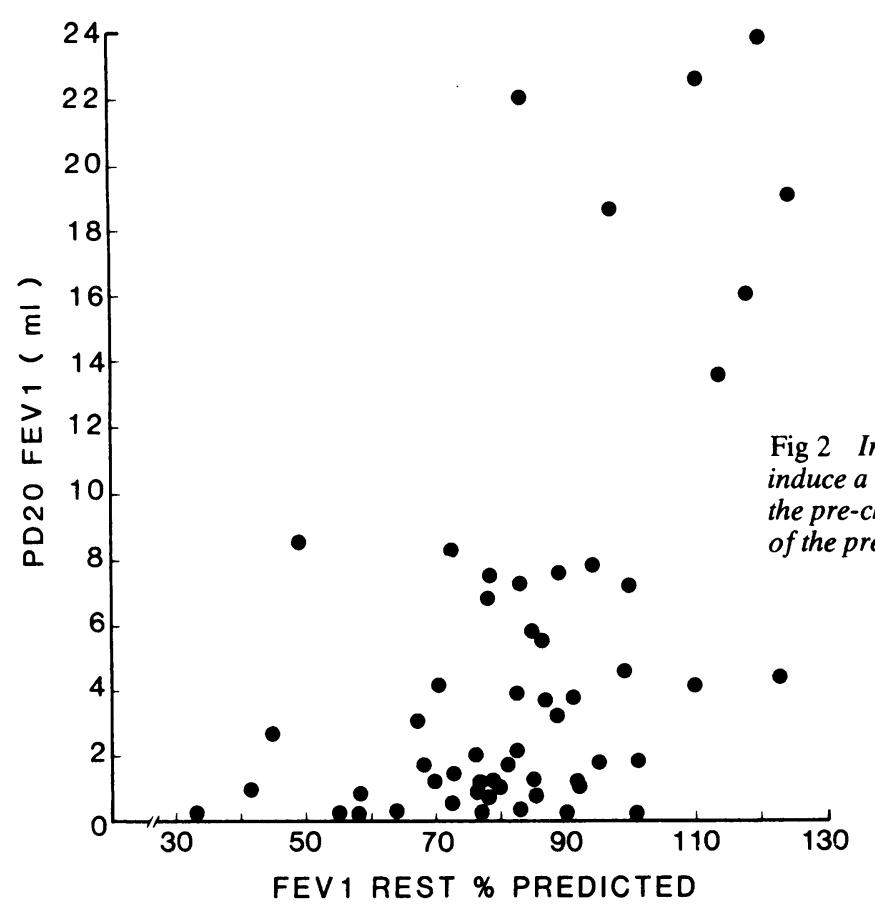

required up to $24 \mathrm{ml}$ to induce a $20 \%$ fall in $\mathrm{FEV}_{1}$.

The levels of $\mathrm{FEV}_{1}$ before challenge (after the inhalation of 401 room air) varied between patients (mean percentage predicted (SD) $83.4 \%$ (19.7). The relationship between the delivered dose required to induce a $20 \%$ fall in $\mathrm{FEV}$, and the prechallenge level of $F E V_{1}$ is illustrated in figure 2 . For the 55 patients there was a significant correlation between the resting level of $F E V_{1}$ and the $P_{20}$. The relationship was no longer evident, however, when the seven patients with a $P D_{20}$ greater than $10 \mathrm{ml}$ were excluded (table 1 , equation 4 ).

In 11 patients who had a mean maximum fall in $\mathrm{FEV}_{1}$ of $42.6 \%$ (SD 7.7) the values for FEV returned to $110.6 \%(42.0)$ of the pre-challenge level within 15 minutes after the administration of salbutamol. In 21 patients (mean fall in FEV, $31.9 \%$ (SD 8.5) in whom spontaneous recovery was allowed to occur the values for $F E V_{1}$ returned to 79.0 (SD 11.7) of the pre-challenge level within 15 minutes.

The relationship between the dose delivered and the dose of water retained is given in table 1 for the 44 asthmatic patients in whom it was measured. The mean percentage of the delivered dose retained by the 44 asthmatics was $69.6 \%$ (SD 6.4) and for the 16 normal subjects $64.3 \%(10.4)$. There was no correlation between the amount of water retained and the resting level of $\mathrm{FEV}_{1}$ expressed as a percentage of the predicted value (table 1 ).
Individual values for the patients who performed two challenge tests with distilled water are given in table 2 . For the 12 patients who performed two tests within six months there was no significant difference in the pre-challenge levels of $\mathrm{FEV}_{1}$ expressed as a percentage of the predicted value (test $183.7 \%$ (SD 19.0 ), test $281.9 \%$ (SD 21.4)). There was no significant difference in the percentage fall in FEV, recorded after an equivalent dose of water and the coefficient of variation for the two tests was $30 \%$.

There was a highly significant reduction in the response in FEV 1 when the same dose of water was given after a 40-minute interval ( $p<0.001)$. For this group of 10 patients the levels of FEV 1 measured before the second test $(72.8 \%(18.7)$ of predicted) were significantly lower $(p<0.005)$ than the values for $\mathrm{FEV}$ observed before the initial challenge $(81.8 \%(16.9)$ of predicted). Although the reduction in $\mathrm{FEV}_{1}$ was significantly less for the same dose of water delivered, bronchial reactivity was still evident at higher doses of water. Seven of the 10 patients still had falls in FEV, greater than $20 \%$ of the initial level. Thus complete refractoriness did not occur in these subjects. For the remaining three subjects (Nos 20, 21, and 23) a fall in FEV greater than $20 \%$ was not recorded after the inhalation of more than $17 \mathrm{ml}$, when the test was terminated.

In eight of the 10 patients. who performed an inhalational challenge with distilled water inspired at a temperature of $22 \cdot 2^{\circ}\left(\mathrm{SD} 1 \cdot 6^{\circ}\right) \mathrm{C}$ and $35 \cdot 8^{\circ}\left(0 \cdot 9^{\circ}\right) \mathrm{C}$ 
Table 2 Individual values for the provoking dose (PD $\mathrm{ml}$ ) of water and the change in forced expiratory volume in one second as a percentage of the pre-challenge value (\% fall in FEV ) at this dose for repeat challenge within six months* and after 40 minutes $\dagger$ and with change in the temperature of the inhaled water $\ddagger$

\begin{tabular}{|c|c|c|c|c|c|c|c|c|c|c|c|}
\hline \multicolumn{4}{|c|}{$\%$ fall in $F E V_{1}^{*}$} & \multicolumn{4}{|c|}{$\%$ fall in $F E V_{1}^{\dagger}$} & \multicolumn{4}{|c|}{$\%$ fall in $F E V_{1} \ddagger$} \\
\hline Case No & $P D m l$ & Test 1 & Test 2 & Case No & $P D \mathrm{ml}$ & Test 1 & Test 2 & Case No & $P D \mathrm{ml}$ & Test 1 & Test 2 \\
\hline $\begin{array}{l}1 \\
2 \\
3 \\
4 \\
5 \\
6 \\
7 \\
8 \\
9 \\
10 \\
11 \\
12 \\
\text { Mean } \\
\text { SD } \\
\text { p }\end{array}$ & $\begin{array}{r}1.9 \\
0.9 \\
1.4 \\
3.0 \\
1.4 \\
1.9 \\
1.4 \\
6.2 \\
1.9 \\
20.1 \\
1.9 \\
24.3\end{array}$ & $\begin{array}{l}33 \cdot 5 \\
58 \cdot 0 \\
42 \cdot 0 \\
28 \cdot 1 \\
22 \cdot 0 \\
36.9 \\
48.9 \\
29 \cdot 3 \\
51 \cdot 0 \\
30 \cdot 0 \\
43 \cdot 0 \\
21 \cdot 0 \\
37 \cdot 8 \\
11.5\end{array}$ & $\begin{array}{r}35 \cdot 5 \\
24 \cdot 0 \\
34.9 \\
42 \cdot 9 \\
20 \cdot 7 \\
30 \cdot 5 \\
36 \cdot 9 \\
31 \cdot 1 \\
42 \cdot 0 \\
21 \cdot 0 \\
45 \cdot 8 \\
18 \cdot 6 \\
32 \cdot 0 \\
8.3\end{array}$ & $\begin{array}{l}13 \\
14 \\
15 \\
16 \\
17 \\
18 \\
19 \\
20 \\
21 \\
22 \\
23 \\
-\end{array}$ & $\begin{array}{r}1.9 \\
7.3 \\
3.0 \\
5.1 \\
0.9 \\
3.0 \\
1.4 \\
8.3 \\
15.8 \\
1.9 \\
12.6\end{array}$ & $\begin{array}{c}37 \cdot 3 \\
26 \cdot 1 \\
42 \cdot 1 \\
35 \cdot 2 \\
31 \cdot 0 \\
39 \cdot 9 \\
29 \cdot 5 \\
26 \cdot 9 \\
32 \cdot 0 \\
29 \cdot 8 \\
46 \cdot 2 \\
34.2 \\
6.5 \\
<0\end{array}$ & $\begin{array}{r}17.8 \\
11.4 \\
17.7 \\
10.5 \\
15.6 \\
16.3 \\
12.5 \\
7.5 \\
4.9 \\
6.0 \\
27.5 \\
13.4 \\
6.5\end{array}$ & $\begin{array}{l}24 \\
25 \\
26 \\
27 \\
28 \\
29 \\
30 \\
31 \\
32 \\
33 \\
-\end{array}$ & $\begin{array}{r}29 \cdot 6 \\
6 \cdot 8 \\
7 \cdot 3 \\
10 \cdot 6 \\
10 \cdot 6 \\
1 \cdot 5 \\
2 \cdot 5 \\
14 \cdot 2 \\
1.5 \\
2 \cdot 5 \\
-\end{array}$ & $\begin{array}{l}40 \cdot 2 \\
39.8 \\
26.9 \\
28 \cdot 1 \\
22 \cdot 9 \\
20 \cdot 0 \\
25 \cdot 0 \\
12.5 \\
42 \cdot 7 \\
46 \cdot 0 \\
- \\
\overline{30} \\
11 \cdot 4\end{array}$ & $\begin{array}{l}0 \\
0 \\
29 \cdot 1 \\
30 \cdot 0 \\
30 \cdot 0 \\
28 \cdot 3 \\
17 \cdot 5 \\
30 \cdot 6 \\
34 \cdot 9 \\
20 \cdot 5 \\
- \\
22 \cdot 1 \\
12 \cdot 7 \\
\text { NS }\end{array}$ \\
\hline
\end{tabular}

$\ddagger$ Test 1: mean inspired temperature $\left(\mathrm{T}_{\mathrm{i}}^{\circ}\right) 22^{\circ} \mathrm{C} \pm 1 \cdot 6$; test $2 \mathrm{~T}_{\mathrm{i}}^{\circ} \mathrm{C} 35 \cdot 8 \pm 0 \cdot 9$.

the response was reproducible. One patient (No 24) had no response after $29 \mathrm{ml}$ aerosol had been inhaled at $36^{\circ} \mathrm{C}$. A second patient (No 25), who had no reduction in $\mathrm{FEV}_{1}$ at the equivalent dose $(6.8 \mathrm{ml})$ of water inhaled at $36^{\circ} \mathrm{C}$, had a $27 \%$ fall in $\mathrm{FEV}$, after $22 \mathrm{ml}$, showing that bronchial reactivity was still present at the higher temperature.

Individual values for the percentage fall in FEV after the same dose of water or $3.6 \%$ saline had been delivered on separate occasions with and without prior medication with sodium cromoglycate, atropine, and verapamil are given in table 3 . A dose-response curve is illustrated for one patient in figure 3. None of the drugs administered induced a significant change in $\mathrm{FEV}_{1}$ in the 15 minutes before challenge. Similarly, there was no change in FEV after the inhalation of $5 \mathrm{ml} 0.9 \%$ saline given as a placebo for verapamil.
When sodium cromoglycate was given before challenge the reduction in FEV, for the same dose of water or saline was less in all patients. Individual values for the percentage protection afforded by sodium cromoglycate, atropine, and verapamil are given in table 3 . A value of $60 \%$ was taken as significant protection from the drug. This value is twice the value for the coefficient of variation recorded in the group of 12 patients who had two challenge tests repeated within six months.

For the equivalent dose of water, sodium cromoglycate afforded a mean protection (SD) of $81.8 \%$ $(20.3)$ and eight of the nine patients had less than $40 \%$ of the mean response observed on the control. Similarly, with the same dose of $3.6 \%$ saline sodium cromoglycate gave significant protection to seven patients and the mean index of protection was $75.7 \%$ (SD 27.6). The response to atropine was

Table 3 Individual values for the provoking dose (PD $\mathrm{ml}$ ) of water and saline and the change in forced expiratory $\frac{D}{0}$ volume in one second expressed as a percentage of the pre-challenge value (\% fall in FEV $)$ induced by that dose with and

Water challenge: \% fall in FEV,

\begin{tabular}{|c|c|c|c|c|}
\hline Case No & $P D \mathrm{ml}$ & Control & $S C G$ & Atropine \\
\hline $\begin{array}{l}34 \\
35 \\
36 \\
37 \\
38 \\
39 \\
40 \\
41 \\
42 \\
\text { Mean } \\
\text { SD }\end{array}$ & $\begin{array}{r}1.9 \\
3.0 \\
1.4 \\
24.3 \\
1.9 \\
0.9 \\
2.5 \\
5.1 \\
3.0\end{array}$ & $\begin{array}{l}47 \cdot 3 \\
19 \cdot 0 \\
39 \cdot 2 \\
24 \cdot 2 \\
36 \cdot 9 \\
48 \cdot 8 \\
48 \cdot 9 \\
45 \cdot 4 \\
28 \cdot 1 \\
37 \cdot 5 \\
11 \cdot 3 \\
\end{array}$ & $\begin{array}{r}7 \cdot 0(85) \\
13 \cdot 0(32) \\
1 \cdot 5(96) \\
5 \cdot 1(79) \\
7 \cdot 5(80) \\
3 \cdot 3(93) \\
11 \cdot 0(78) \\
0.100) \\
2 \cdot 1(93) \\
5 \cdot 6(81 \cdot 8) \\
4 \cdot 4(20 \cdot 3)\end{array}$ & $\begin{array}{l}46 \cdot 5(2) \\
48 \cdot 8(0) \\
10 \cdot 5(73) \\
2 \cdot 0(92) \\
33 \cdot 9(8) \\
19 \cdot 5(60) \\
34 \cdot 6(29) \\
4 \cdot 0(91) \\
12 \cdot 0(57) \\
23 \cdot 5(45 \cdot 8) \\
17.9(37 \cdot 0)\end{array}$ \\
\hline $\mathrm{p}$ & \multicolumn{4}{|c|}{$<0.001$} \\
\hline $\mathrm{p}$ & & & NS & \\
\hline
\end{tabular}


ultrasonically nebulised water was observed within four minutes, so the test is very rapid for use as a routine provocation test. The least responsive patients, however, took 20-25 minutes to be tested.

Many patients were highly reactive to the effects of inhaled water at a time when their FEV, was within normal limits. It was not possible, however, to predict sensitivity to the inhaled water from the resting level of FEV in the 48 patients who had a $\mathrm{PD}_{20}$ less than $10 \mathrm{ml}$. In 16 non-asthmatic subjects there was no $\mathrm{PD}_{20}$ recorded after the inhalation of $33 \mathrm{ml}$ water or $3.6 \%$ saline. In the asthmatic patients the highest dose delivered to elicit a positive response was $23.8 \mathrm{ml}$. Since normal subjects had no response after $33 \mathrm{ml}$ they would seem to be well separated from the asthmatic population.

Because there was relatively little variation in the proportion of water retained (despite enormous differences in the resting level of airways obstruction) we have not corrected the values for the delivered dose of water or saline. Although the amount of water retained was similar in the patients and normal subjects we do not know the site of deposition of the aerosol, which may have been different in the patients with airways obstruction before challenge.

It has been suggested that bronchial reactivity is enhanced in the presence of bronchoconstriction. ${ }^{5}$ We did not observe an increased reactivity to water in relation to resting lung function either in the group of 55 patients or in a patient who performed the same challenge on several occasions. In fact, we observed an appreciable reduction in airway response to the same dose of water given $\mathbf{4 0}$ minutes later at a time when airways obstruction was still present after the initial challenge. Some bronchial reactivity was, however, still present in seven of the 10 patients.

The increased tolerance of water inhalation may be due to availability of fewer "osmosensitive" receptor sites or to failure of the water to reach the site as a result of a change in membrane permeability. Perhaps changes in osmolarity within the respiratory tract induce a "down regulation" of receptors resulting in desensitisation and subsequent tolerance. Further studies are required to elucidate the decreased responsiveness observed with a challenge repeated within an hour.

The mechanism by which a reduction in FEV occurs in patients with asthma in response to the inhalation of water and $3.6 \%$ saline is unknown. The

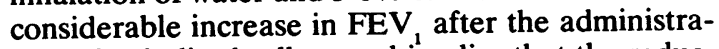
tion of nebulised salbutamol implies that the reduction in FEV , which occurred after the inhalation of these aerosols was due to contraction of airway smooth muscle. The mechanism by which bronchoconstriction occurs presumably relates to the osmolarity of the aerosol. Isotonic saline has little, if any, effect on FEV, when delivered by ultrasonic nebuliser ${ }^{1}$ and it had no effect in a dose of $5 \mathrm{mlo}$ delivered by an Acorn nebuliser in this study. Dis-등 tilled water and $3.6 \%$ saline appear to be equally potent in causing bronchoconstriction and similar $\overparen{Q}$ responses in FEV, have been observed in ourg laboratory for asthmatic patients challenged with ${ }_{3}^{\text {s }}$ $20 \%$ dextrose ${ }^{1}$ A significant bronchoconstrictor. stimulus is unlikely to be explained by the fact that $\overrightarrow{\vec{\omega}}$ the aerosol was inhaled at room temperature sinceo in eight patients the response was reproducible $\overrightarrow{\vec{x}}$ when the temperature of the aerosol was increased to $36^{\circ} \mathrm{C}$.

The observation that sodium cromoglycate was effective in inhibiting the response in all patients suggests several possibilities. Mediators from masto cells in the bronchial mucosa may be released in response to hypotonic and hypertonic solutions. $>$ Mast cells in vitro are known to release histamine in hypotonic solutions and basophils have beenreported to release histamine in hypertonic solu $-\infty$ tions. ${ }^{67}$ Possibly sodium cromoglycate protects the cell against conformational changes in response to change in the osmotic pressure of the surrounding fluid. ${ }^{8}$ Transient changes in the environment of mast cells or irritant receptors may be all that is requireक्. to induce mediator release and smooth muscle con£ traction, either directly or via the vagus nerve. It is now thought that sodium cromoglycate may reduces reflex bronchoconstriction by an action on the post? ganglionic arm of the vagal reflex, but this has been? shown only in dogs. ${ }^{9}$

A protective effect was noted in some patient after pretreatment with atropine, which suggestơ that reflex bronchoconstriction may have been occurring in these patients at least. Others, however had an increased response after atropine, which makes the results difficult to interpret. Although $1 \%$ solution was used, most patients complained of a severe dry mouth and throat and for this reasop the dose was reduced to $0.1 \%$ for two patients (No표. 34 and 37). Patient 36 was as well protected bs $0.1 \%$ on challenge with water as by $1.0 \%$ on chatlenge with $3.6 \%$ saline. The period of 10-19 minutes between administration and challenge wa\$ insufficient to observe the usual bronchodilating effect of atropine, ${ }^{10}$ but it is long enough for atropine to prevent induced asthma. ${ }^{11}$ Allegra an Bianco $^{2}$ made similar observations in studying the effect of sodium cromoglycate but failed to show an inhibition of the airway response to distilled wate after pretreatment with the anticholinergic iprap ropium bromide.

Since mast cell release is calcium dependent it wag considered that verapamil (a calcium antagonist) 
might inhibit the response. If mast cells are osmotically labile, however, calcium is unlikely to be required for the release of mediators. The failure of verapamil in most patients therefore does not seem surprising. A dose of $12.5 \mathrm{mg}$ was chosen as it is well tolerated and has been shown to inhibit exerciseinduced asthma in some, though not all, patients. ${ }^{12}$ In a dose of $12.5 \mathrm{mg}$ it is, however, ineffective in preventing histamine-induced or methacholineinduced asthma. ${ }^{13}$ Possibly a higher dose may have had a significant protective effect, although we have found $120 \mathrm{mg}$ verapamil, given orally one hour before challenge, to be equally ineffective in protecting against water inhalation.

The Acorn nebuliser delivers particles with a mass median diameter similar to that of particles delivered by the ultrasonic nebuliser. The drugs would therefore presumably be delivered to the same site in the lung as the ultrasonic mist, although the density of the particles may not have been the same. In the study of Allegra and Bianco ${ }^{2}$ the failure of ipratropium bromide may have been due to the method of delivery.

In patients in whom two inhalational challenges were carried out we compared the reduction in FEV, after an equivalent dose (either water or $3.6 \%$ saline) in preference to determining the change in $\mathrm{PD}_{20}$ for several reasons. Firstly, many of our patients were exquisitively sensitive to small doses of water. Extrapolating a $\mathrm{PD}_{20}$ from a dose-response curve when a change of $65 \%$ in FEV occurred in response to the inhalation of $0.5 \mathrm{ml}$ water presented some difficulties. Secondly, by using the same dose of water or saline to evaluate the effect of a repeated challenge, with or without premedication, we have been able to document changes well above the threshold of abnormal reactivity (that is, a greater than $20 \%$ reduction in $\mathrm{FEV}_{1}$ ). This approach to evaluating drug treatment is commonly used in exercise-induced hnlnchoconstrasthma. ${ }^{11}$

Documenting the stimulus required to induce a $20 \%$ reduction in $\mathrm{FEV}_{1}$ is a useful technique for studying sensitivity within a population of asthmatic patients. We believe that documentation of individual reactivity and the change induced by drugs may be of major clinical significance.

The results of this and an earlier study ${ }^{1}$ from this laboratory indicate that patients with asthma are exquisitively sensitive to a change in osmolarity within the respiratory tract. We have previously suggested that the evaporation of water, which occurs from the bronchial mucosa during exercise, acts as a transient hypertonic stimulus and that this change in osmolarity may be an important mechanism in exercise-induced asthma. ${ }^{14}$
Inhalational challenges with ultrasonically nebulised hypotonic and hypertonic solutions in patients with asthma provides a useful technique for comparing the response to osmotic stimulus, whether extrinsic (for example, inhalation of fog) or intrinsic (for example, water loss by evaporation). In this way many triggering factors known to induce asthma may be shown to act through a common pathway.

RES was supported by the Maureen Thompson asthma research grant of the National Health and Medical Research Council of Australia.

\section{References}

' Schoeffel RE, Anderson SD, Altounyan REC. Bronchial hyperreactivity in response to inhalation of ultrasonically nebulised solutions of distilled water and saline. Br Med J 1981;283:1285-7.

${ }^{2}$ Allegra L, Bianco S. Non-specific broncho-reactivity obtained with an ultrasonic aerosol of distilled water. Eur J Respir Dis 1980;61 suppl 106:41-9.

${ }^{3}$ Goldman HI, Becklake MR. Respiratory function tests: normal values at medium altitudes and the prediction of normal results. Am Rev Respir Dis 1959;79:45767.

${ }^{4}$ Snedecor GW, Cochran WG. Statistical methods. Ames, Iowa: Iowa State University Press, 1967.

5 Tattersfield AE. Measurement of bronchial reactivity: a question of interpretation. Thorax 1981;36:561-5.

' Findlay SR, Lichtenstein LM. Basophil "releasability" in patients with asthma. Am Rev Respir Dis 1980;122:53-9.

${ }^{7}$ Kaliner M, Austen KF. Cyclic AMP, ATP and reversed anaphylactic histamine release from rat mast cells. $J$ Immunol 1974;112:664-74.

${ }^{8}$ Padawer J. Mast-cell structure: implications for normal physiology and degranulation. In: Pepys J, Edwards AM, eds. The mast cell: its role in health and disease. Tunbridge Wells: Pitman Medical, 1979:1-8.

${ }^{9}$ Dixon M, Jackson DM, Richards IM. The action of sodium cromoglycate on "C" fibre endings in the dog lung. Br J Pharmacol 1980;70:11-3.

${ }^{10}$ Altounyan REC. Variation of drug action on airway obstruction in man. Thorax 1964;19:406-15.

$"$ Anderson SD, Seale JP, Ferris L, Schoeffel RE, Lindsay DA. An evaluation of pharmacotherapy for exerciseinduced asthma. $J$ Allergy Clin Immunol 1979;64:612-24.

${ }^{12}$ Patel KR. Calcium antagonists in exercise-induced asthma. Br Med J 1981;282:932-3.

${ }^{13}$ Patel KR. The effect of verapamil on histamine and methacholine-induced bronchoconstriction. Clin Allergy 1981;11:441-7.

${ }^{14}$ Anderson SD, Schoeffel RE, Follet R, Perry CP, Daviskas E, Kendall M. Sensitivity to heat and water loss at rest and during exercise in asthmatic patients. Eur $J$ Respir Dis 1982;63:459-71. 